\title{
Medikamentell forebygging ved prediabetes - ingen hensikt? 遇
}

Ikke-medikamentelle tiltak med vektreduksjon forebygger utvikling av type 2-diabetes hos personer med glukoseintoleranse. Hvorvidt medikamentelle tiltak kan forebygge type 2-diabetes, er derimot mer omdiskutert. I NAVIGATOR-studien, som ble publisert i 2010, forsøkte man å forebygge type 2-diabetes og kardiovaskulære hendelser ved hjelp av nateglinid, alternativt valsartan. Forfatterne, som deltok i studien, diskuterer her funnene i lys av tidligere litteratur.

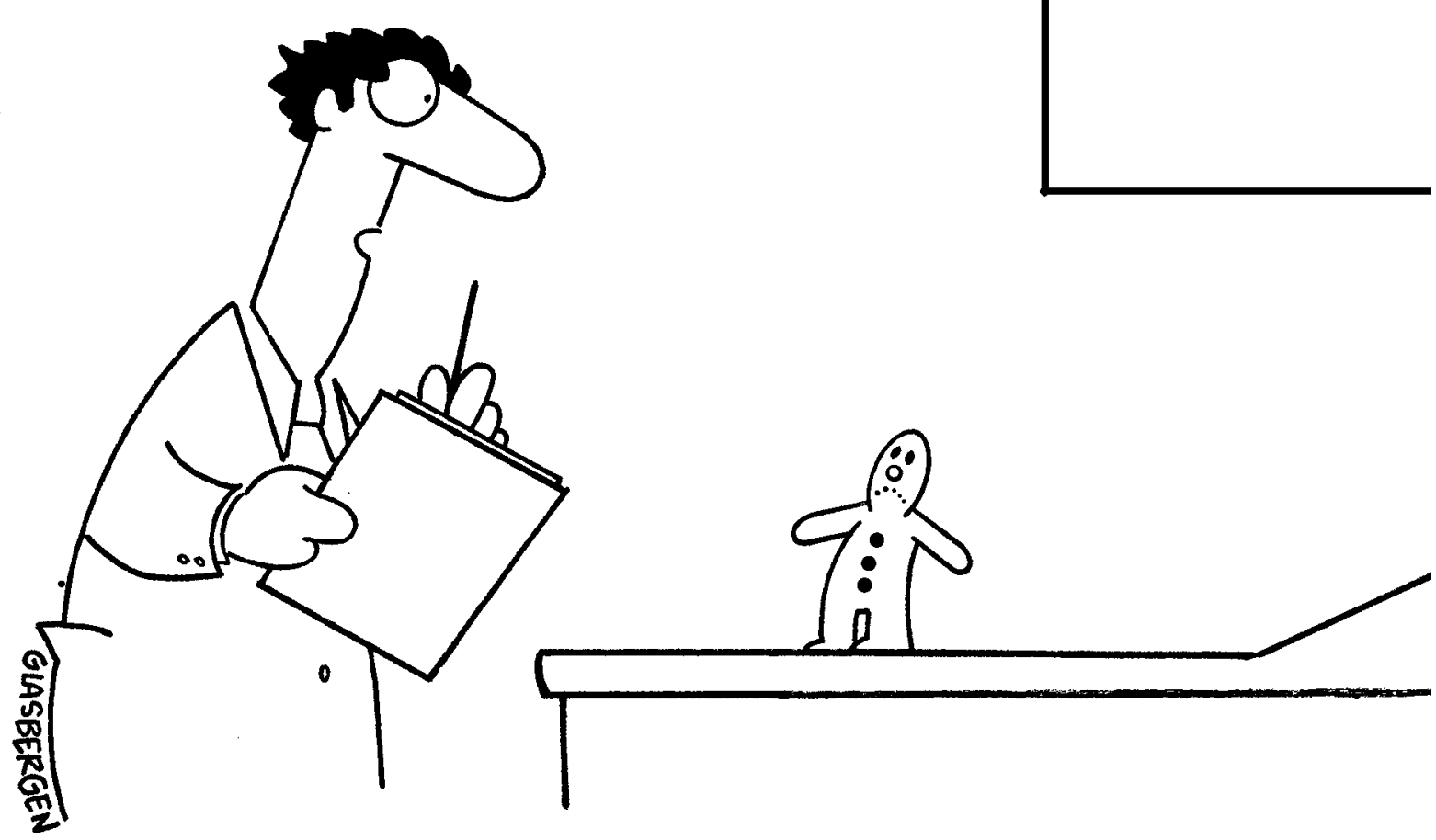

"Your blood sugar is too high."

Illustrasjon @ Randy Glasbergen

NAVIGATOR-studien (Nateglinide and Valsartan in Impaired Glucose Tolerance Outcomes Research) ble publisert i to artikler i New England Journal of Medicine i $2010(1,2)$. Man forsøkte medikamentelt å forebygge henholdsvis diabetes og kardiovaskulære hendelser hos mer enn 9000 personer med prediabetes (glukoseintoleranse) i 40 land.

Behandling med metformin (3), acarbose (4), og rosiglitazon (5) ser i tidligere studier ut til å redusere utviklingen av type 2-diabetes. Angiotensinkonvertasehemmere (ACE-hemmere) og AII-blokkere er assosiert med færre diabetestilfeller i assosiasjonsstudier. I en nylig publisert intervensjonsstudie ser dette ikke ut til å gjelde ramipril (5).
Hva forteller NAVIGATOR-studien? I NAVIGATOR-studien ble det blodsukkersenkende medikamentet nateglinid og AIIblokkeren valsartan undersøkt mot placebo. For alle deltakerne var det i tillegg lagt inn et livsstilsintervensjonsprogram som tok sikte på $5 \%$ vektreduksjon og 150 minutter fysisk aktivitet per uke. $10 \%$ av deltakerne nådde vektreduksjonsmålet. Til sammen 9306 personer ble fulgt i opptil sju år.

Det var ingen forskjell mellom nateglinid og placebo når det gjaldt utvikling av diabetes eller kardiovaskulære hendelser. Valsartan, på sin side, reduserte forekomsten av diabetes med $14 \%$ sammenliknet med placebo, men påvirket ikke de kardiovaskulære hendelsene.

\section{Lærte vi noe?}

NAVIGATOR er en viktig studie siden man der testet sentrale hypoteser fra epidemiologisk forskning. Den hurtigvirkende insulinfrigjøreren nateglinid reduserer ikke utvikling av diabetes på sikt. Faktisk var totimersglukosenivået høyere i nateglinidgruppen enn i placebogruppen ved studieslutt, sannsynlig fordi den orale glukosebelastningen ble utført medikamentfastende. $\mathrm{HbA}_{1 \mathrm{c}}$ var således 0,2 prosentpoeng lavere i nateglinidgruppen $(6,1 \%$ versus $6,3 \%)$. På den annen side kan det virke som om reduksjon av mer alvorlig hyperglykemi, som ved diabetes, kan ha en gunstig effekt når det er gått mer enn 10-15 år (6), mye lengre tid enn det vanlige intervensjonsstudier går over. 
Det er usikkert hvorfor metformin, acarbose eller rosiglitazon skulle kunne forebygge diabetes, mens nateglinid ikke gjør det. Om det kan tilskrives ulik virkningsprofil, forskjeller i studiepopulasjoner eller begge deler, er uvisst. To studier på tolbutamid $(7,8)$ og én studie på sulfonylureapreparater (9), begge med en virkningsprofil ikke ulik den til nateglinid, viste heller ikke diabetesforebyggende effekt.

Valsartan hadde en moderat diabetesforebyggende effekt som tilsynelatende var større enn hva man så med ramipiril i DREAM-studien, der ramipril reduserte forekomsten av diabetes med $9 \%$ - uten statistisk signifikans (5). Hvorfor intervensjon på renin-angiotensin-systemet skulle forebygge diabetes, er foreløpig uavklart.

Valsartan forebygde ikke kardiovaskulære hendelser i NAVIGATOR-studien, ulikt det som var tilfellet i tidligere studier med valsartan og andre medikamenter i samme klasse. I de tidligere studiene var imidlertid personer med høyere risikoprofil inkludert. I NAVIGATOR-studien hadde bare $24 \%$ av deltakerne kardiovaskulær sykdom ved inklusjonstidspunktet og kun tre av fire hadde hypertensjon, og de gjennomførte et livsstilsprogram som må ha vært $i$ alle fall delvis vellykket. Det var også utstrakt bruk av andre medikamenter mot kardiovaskulær sykdom. Dessuten var den daglige dosen valsartan i NAVIGATOR bare halvparten av det man har brukt i tidligere studier.

Konklusjonen er at nateglinid, som sulfonurea, ikke beskytter mot utvikling av type 2-diabetes. Behandlingen ser heller ikke ut til å senke den kardiovaskulære risikoen hos personer med glukoseintoleranse. Valsartan kan ha en diabetesforebyggende plass i behandlingen av personer med glukoseintoleranse og hypertensjon, men påvirker neppe den kardiovaskulære risiko.

\section{Erik Snorre Øfjord}

Arne Skag

Senter for kliniske studier, Bergen

\section{Steinar Helberg}

Dagfinn Aarskog

Colosseumklinikken, Oslo

Knut Risberg

Skedsmo medisinske senter, Skedsmo

Trine Jacobsen

Ullevålsveien legesenter, Oslo

Samuel Nasrala

Legekontoret, Skolegaten, Strømmen

Sjur Bakken

Skårer legesenter, Skårer

Unni Syversen

St. Olavs hospital

og

Norges teknisk-naturvitenskapelige universitet

\section{Trond Jenssen}

trond.jenssen@ous-hf.no

Avdeling for organtransplantasjon,

gastroenterologi og nefrologi

Oslo universitetssykehus, Rikshospitalet

og

Institutt for klinisk medisin

Universitetet i Tromsø
Forfatterne representerer ikke nødvendigvis oppfatningen til den internasjonale forskergruppen i NAVIGATOR-studien.

Erik Snorre Øfjord (f. 1950) har bakgrunn fra basalfagene (fysiologi) og har jobbet med kliniske studier de siste 18 år på heltid. Ingen oppgitte interessekonflikter.

Arne Skag (f. 1950) er spesialist i indremedisin. Oppgitte interessekonflikter: Har mottatt bidrag fra Novartis for inklusjon av pasienter til studien.

Steinar Helberg (f. 1954) er allmennlege og daglig leder ved Allmennseksjonen ved Colosseumklinikken i Oslo.

Oppgitte interessekonflikter: Har mottatt honorar fra Novartis.

Dagfinn Aarskog (f. 1973) er ansatt ved Allmennseksjonen ved Colosseumklinikken i Oslo.

Ingen oppgitte interessekonflikter.

Knut Risberg (f. 1956) er spesialist $\mathrm{i}$ indremedisin og allmennmedisin. Oppgitte interessekonflikter: Har mottatt foredragshonorar og bidrag for inklusjon av pasienter til studien fra Novartis.

Trine Jacobsen er spesialist i indremedisin. Oppgitte interessekonflikter: Har mottatt foredragshonorar fra Novartis, BMS, AstraZeneca og MSD og bidrag fra Novartis for inklusjon av pasienter til studien.

Samuel Nasrala (f. 1950) er spesialist i allmennmedisin.

Oppgitte interessekonflikter: Har mottatt konsulenthonorar og bidrag for inklusjon av pasienter til studien fra Novartis.

Sjur Bakken (f. 1953) er spesialist i allmennmedisin og samfunnsmedisin og kommuneoverlege i Aurskog-Høland. Oppgitte interessekonflikter: Har mottatt reisestøtte og bidrag for inklusjon av pasienter til studien fra Novartis.

Unni Syversen er spesialist i indremedisin, lungemedisin og endokrinologi. Hun er professor ved Norges teknisk-naturvitenskapelig universitet og overlege ved Avdeling for endokrinologi. Ingen oppgitte interessekonflikter.

Trond Jenssen (f. 1955) er spesialist i nefrologi og indremedisin. Han er overlege ved Nyreseksjonen ved Avdeling for organtransplantasjon og professor II i indremedisin ved Universitetet i Troms $\varnothing$. Nefrologi, diabetes og hypertensjon er primære forskningsfelter. Oppgitte interessekonflikter: Har mottatt reisestøtte og konsultasjons- og foredragshonorar fra Novartis, Bristol Myers-Squibb, EliLilly, Meda og MSD.
Litteratur

1. Holman RR, Haffner SM, McMurray JJ et al. Effect of nateglinide on the incidence of diabetes and cardiovascular events. N Engl J Med 2010; 362 1463-76.

2. McMurray JJ, Holman RR, Haffner SM et al. Effect of valsartan on the incidence of diabetes and cardiovascular events. N Engl J Med 2010; 362: 1477-90.

3. Knowler WC, Barrett-Connor E, Fowler SE et al. Reduction in the incidence of type 2 diabetes with lifestyle interventions or metformin. N Engl J Med 2002; 346: 393-403.

4. Chiasson JL, Josse RG, Gomis R et al. Acarbose for prevention of type 2 diabetes mellitus: the STOP-NIDDM randomised trial. Lancet 2002; 359 2072- 7 .

5. Gerstein HC, Yusuf S, Bosch J et al. Effect of rosiglitazone on the frequency of diabetes in patients with impaired glucose tolerance or impaired fasting glucose: a randomised controlled trial. Lancet 2006; 368: 1096-105. Erratum i: Lancet 2006; 368 1770

6. Holman RR, Paul SK, Bethel MA et al. Long-term follow-up after tight control of blood pressure in type 2 diabetes. N Engl J Med 2008; 359: 1565-76.

7. Sartor G, Scherstén B, Carlström S et al. Ten-year follow-up of subjects with impaired glucose tolerance: prevention of diabetes by tolbutamide and diet regulation. Diabetes 1980; 29: 41-9.

8. Keen H, Jarrett RJ, McCartney P. The ten-year follow-up of the Bedford survey (1962-1972): glucose tolerance and diabetes. Diabetologia 1982; 22: 73-8

9. Karunkaran S, Hammersley MS, Morris RJ et al. The Fasting Hyperglycemia Study: III. Randomized control trial of sulfonylurea therapy in subjects with increased but not diabetic fasting plasma glucose. Metabolism 1997; 46 (suppl 1): 56-60.

Mottatt 8.3. 2011, første revisjon innsendt 27.4. 2011, godkjent 26.5. 2011. Medisinsk redaktør Are Brean.

Engelsk oversettelse av hele artikkelen på www.tidsskriftet.no 